\title{
ПРЕДОСТАВЛЕНИЕ ГОСУДАРСТВЕННЫХ И МУНИЦИПАЛЬНЫХ УСЛУГ В ЭЛЕКТРОННОЙ ФОРМЕ НА ЭТАПЕ ФОРМИРОВАНИЯ ИНФОРМАЦИОННОГО ОБЩЕСТВА
}

\begin{abstract}
Аннотация. В данной статье автор указывает на современный феномен Информатизация, которая оказывает значительное влияние на развитие общества, на взаимоотношения государства и граждан. $B$ статье автором показана эволюция понятий "Информационное общество», "Глобальное информационное общество». Рассматривается вопрос о совершенствовании российской нормативной правовой базы в условиях глобального информационного общества. Автором подчеркивается значимость правового информирования граждан через открытость и доступность, как одну из основных задач деятельности органов государственной власти и местного самоуправления, при этом остается открытый вопрос о необходимости уточнения нормативных правовых формулировок. В решении данной проблемы использовался метод теоретического исследования отечественных и зарубежных ученых, работы которых посвящены сущности и закономерности формирования национального и глобального информационного общества. Основными выводами сделанными автором заключаются в том, что при высоких темпах формирования законодательных актов и быстро изменяющаяся ситуация в информационном обществе появляются новые проблемы: подготовка нормативных правовых актов не всегда соответствует изменяющимся условиям, проблематична также интеграция актов по смежным проблемам.

Ключевые слова: общество, информационное общество, глобальное информационное общество, зарубежное законодательство, законодательство, нормативный правовой акт, правовое регулирование, информационная политика, государство, государственные информационные услуги.

Abstract. Computerization has a significant impact on the development of the society, on the relations between the state and citizens. The article shows the evolution of the concepts "Information society" and "Global information society». The author discusses the improvement of Russian normative legal base in the context of the global information society, emphasizes the importance of legal awareness of citizens by means of openness and accessibility as one of the main tasks of public authorities and local self-government. The author demonstrates the necessity to clarify normative legal formulations. The author applies the method of theoretical research of the works of Russian and foreign scholars, whose studies focus on the essence and the patterns of formation of the national and global information society. The author concludes that, with the rapid formation of legal acts and the change of the situation in the information society, new problems emerge: the preparation of normative legal acts doesn't always conform with the changing conditions; the integration of legislation in the allied branches is also problematic.
\end{abstract}

Key words: legal regulation, normative legal act, legislation, foreign legislation, global information society, information society, society, information policy, state, state information services.

$\Pi$ онятие информационного общества не является новым - оно возникло в середине 60-х гг. XX века, но с 1970-х и 1980-х гг. его содержание менялось. Множество существующих теорий информационного общества показывает сложность самого определения термина (словосочетания) «информационное общество», понятие остается недостаточно точным как в бизнес-стра- тегиях, социальной и экономической политике, так и в повседневности.

В монографии «Global Information Society: Technology, Knowledge, and Mobility» (MD: Rowan \& Littlefield, 2013) M. I. Wilson, A. Kellerman, K. E. C. Lanham отмечают, что информационное общество как таковое не является новым, а новым является доминирование информации в нашей 


\section{Административное и муниципальное право 1 (97) • 2016}

жизни. Если обеспечить определенный порядок в условиях «века информации», то люди могут определить свое место и понять последствия информационного превосходства. Это важно в решении ключевых вопросов новых технологий и инфраструктур, производства, мобильности общества, информации и знаний и роли отдельных лиц в информационном обществе [38, с. 229].

Термин «информационное общество» достаточно популярен в России, поскольку в этом понятии важную роль так или иначе играет информационно-технологическая сторона развития, а в России использование информационных товаров и услуг в предыдущие годы росло достаточно быстрыми темпами [26, с. 128]. Одно из ранних определений информационного общества дает В.Л. Иноземцев: информационное общество может быть кратко определено как «концепция постиндустриального общества; историческая фаза развития цивилизации, в которой главными продуктами производства являются информация и знания» [16, с. 39].

Формирование информационного общества связывают и с повышением качества жизни, участием значительной части трудоспособного населения в производственной деятельности, связанной с созданием и использованием информационных технологий, расширением юридических прав граждан по поиску, получению, передаче, производству и распространению информации и знаний $[26$, с. 125$]$. Информатизация общества становится необходимым условием и объективной потребностью в развитии экономики, науки, образования, культуры, национальной безопасности России. С целью способствовать развитию информатизации в 2010 г. принята Государственная программа «Информационное общество 2011-2020 гг.» $[24$, С. 193].

Существует множество документов, в которых проблемы формирования информационного общества перенесены на международный уровень [32, c. 8]. Активное международное взаимодействие в этой области началось с подписания лидерами стран «Большой восьмерки» (G8) в г. Окинава (Япония) декларации министров - «Окинавской хартии глобального информационного общества» (7 июля 2000 г.), в которой отмечалось, что информационно-коммуникационные технологии являются одним из наиболее важных факторов, влияющих на формирование современного мира [20].

Деятельность ООН по формированию информационного общества и глобального развития информационно-коммуникационных технологий можно проследить по документам Генеральной Ассамблеи $\mathrm{OOH}$, размещенным на официальном сайте OOH [22]. В области информационных технологий наиболее активно действует специализированное учреждение Организации Объединенных Наций по вопросам образования, науки и культуры ЮНЕСКО. В его деятельности выделяются два важнейших направления - образование и коммуникации и информация. Глобальной сетью ООН в области развития, выступающей за изменения в общественной жизни через подключение стран к источникам знаний, опыта и ресурсов является Программа Развития ООН (ПРООН) [21].

Направления интеграции России в глобальное коммуникационное пространство изложены в «Стратегии развития информационного общества в Российской Федерации» [30], принятой 7 февраля 2008 г. Особое внимание уделяется международному сотрудничеству в области развития информационного общества, где основными направлениями реализации настоящей Стратегии являются: «участие в разработке международных норм права и механизмов, регулирующих отношения в области использования глобальной информационной инфраструктуры, включая вопросы интернационализации управления сетью Интернет; участие в международном информационном обмене; участие в формировании системы международной информационной безопасности, совершенствование взаимодействия правоохранительных органов Российской Федерации и иностранных государств в области предупреждения, выявления, пресечения и ликвидации последствий использования информационных и телекоммуникационных технологий в террористических и иных преступных целях; участие Российской Федерации в международных исследовательских проектах по приоритетным направлениям развития науки, технологий и техники; участие в разработке международных стандартов в сфере информационных и телекоммуникационных технологий, гармонизация национальной системы стандартов и сертификации в этой сфере с международной системой» [30].

Программа Развития Организации Объединенных Наций сотрудничает с Россией с 1993 г., когда было подписано соответствующее Соглашение с Правительством Российской Федерации [21].

Таким образом, развивающееся глобальное информационное общество сегодня представляет качественно новые возможности социализации людей и доступа к накопленным человеческим знаниям, преодоления «цифрового» неравенства, реформирования государственного управления на основе становления электронного правительства и осуществления информационной политики государства по взаимодействию с гражданским обществом в целях обеспечения открытости и прозрачности. Это отражается в общепризнанных принципах и нормах международного права, в за- 
рубежном опыте, а также при формировании государственной политики и в динамике развития информационного права в Российской Федерации $[34$, c. 3].

Глобальное информационное общество представляет этап в развитии современной цивилизации, характеризующийся увеличением роли информации и знаний в жизни общества, доли информационных товаров и услуг, возникновением глобального информационного пространства, обеспечивающего эффективное взаимодействие людей и доступ к мировым информационным ресурсам, удовлетворение общественных и личных информационных потребностей [5, с. 9]. Информация и знания при этом - важнейшие продукты производства и обмена [13, с. 89]. M. I. Wilson, A. Kellerman, K. E. C. Lanham выделяют три основные составляющие глобального информационного общества: технологии, знания и мобильность [38, с. 229].

Исследования отечественных и зарубежных ученых подтверждают, что формирование глобального информационного общества является преобладающим направлением развития и «очевидно во многом будет определять облик уже формирующейся сегодня новой глобальной цивилизации» [16, с. 57]. Число научных публикаций различного характера, посвященных информационной политике, информационным технологиям и коммуникациям в глобальном информационном обществе и близким вопросам значительно как за рубежом [36; 37; 38; 39; 41], так и в России. Предметом исследования является информационное общество, информационная политика в глобальном, региональном, национальном и местном уровнях, информационные технологии как инструмент формирования современного общества. Это подтверждает многоплановость исследуемого феномена и необходимость комплексного подхода к его изучению.

В отечественных публикациях отмечается, что необходимо комплексное изучение теоретических и практических вопросов в области правового регулирования отношений в рамках глобального информационного общества [14, с. 110]. В российской науке в данной области работают И. Л. Бачило [2; 3 ; 4], Н. А. Сидорина [27], И. Н. Забара [9], С. П. Стащенко [29], В. П. Талимончик [31; 32; 33], Г. Г. Шинкарецкая [35], А. И. Химченко [34], О. Н. Забузов [10]. И тем не менее число работ, посвященных вопросам правового регулирования отношений на различных уровнях, возникающих в информационном обществе, невелико, не создано еще авторитетной теоретической базы исследования возникающих проблем с правовой точки зрения.

В целом авторы констатируют, что развитие и распространение новых информационных и телекоммуникационных технологий, имеющее характер глобальной информационной революции, открывает дополнительные возможности для осуществления государственного управления, влияния на политику, экономику, управление, финансы, науку, культуру и другие сферы жизнедеятельности общества как в рамках национальных границ, так и вне $[1$, с. 58]. А. Гуменский выделяет следующие основные группы участников современного глобального информационного общества: государства, крупный бизнес, транснациональные медиакорпорации, гражданские институты, некоммерческие и неправительственные организации, транснациональные социальные сети и индивидуумов [6, с. 33]. К. К. Колин считает, что процесс информатизации имеет мощный потенциал и, конечно, сохранит свою стратегическую значимость в развитии цивилизации, поскольку информатизация является мощным катализатором многих других процессов развития общества, в том числе, создания и внедрения инноваций, новых социальных и энергетических технологий, а также науки, образования и культуры [11, с. 28].

В условиях информационной глобализации изменяются и общественные отношения, которые требуют правового регулирования для обеспечения эффективного взаимодействия граждан с государством, повышения уровня качества доставления государственных и муниципальных услуг, открытости и доступности информации о деятельности государственных органов и муниципальных органов, электронного правосудия и др. [34, с. 7].

Информационные правоотношения, вопросы об унификации правовых дефиниций и другие актуальные теоретические проблемы информационного права в информационной сфере в условиях глобализации требуют дальнейших исследований.

Индекс развития информационно-коммуникационных технологий (ICT Development Index) - это комбинированный показатель, характеризующий достижения стран мира с точки зрения развития информационно-коммуникационных технологий. Россия по общему уровню информатизации значительно уступает передовым промышленно развитым странам, находясь лишь в середине рейтингового списка сетевого развития (включающего и развивающиеся страны). Однако темпы развития информатизации и вовлеченности населения в эти процессы определяются как достаточно высокие. В «Рейтинге стран мира по уровню развития информационнокоммуникационных технологий 2013 года» [25] Россия занимала 40 место с индексом развития 6,19 (занимающая первое место Южная Корея получила индекс 8,57. В тройку лидеров вошли также Швеция $(8,45)$ и Исландия $(8,36))$. В «Рейтинге стран мира по уровню развития информационно-коммуникацион- 


\section{Административное и муниципальное право 1 (97) • 2016}

ных технологий 2014 года» Россия уже занимает 42 место с индексом развития 6,70, в то время как занимавшая первое место в 2013 г. Южная Корея переместилась на второе место и получила индекс 8,85 (первое место в рейтинге 2014 года занимает Дания с индексом 8,86) [40].

Это отражает формирование векторов развития информационного общества как общества гражданского, социального, демократического, правового. Основа развития - осуществление информационной политики государства по взаимодействию с гражданским обществом в целях обеспечения открытости и прозрачности, высокого уровня доступности, построения общества знания, оказания публичных услуг [см.: 14; 34]. В соответствии с концепцией правового обеспечения информационного общества введена модель понимания сути информационного общества, согласно которой оно может быть таковым только при условии, что является обществом гражданским, социальным, демократическим и правовым. В данном случае это позволяет установить связь нарастания гражданственности и развития личности обновляющегося общества с состоянием деятельности по группе социальных функций самого государства и общества в целом. Чем активнее и полноценнее человек в осознании своих прав и обязанностей, тем в большей мере он нуждается в услугах со стороны государственных институтов и структур [3, с. 54]. Информационно-коммуникационные технологии, которые обеспечивают предоставление информационно-коммуникационных услуг, занимают особое место в жизни общества. От качества предоставления информационных услуг зависит уровень развития государства и удовлетворенность граждан [3, с. 54].

Нормотворческая, управленческая и контрольная функции государственного аппарата характеризуются наличием и оборотом значительного объема информации, на основе которой готовятся, принимаются и реализуются государственные решения. Право на доступ к информации о деятельности органов власти важно для граждан, так как прозрачность и открытость в деятельности властных структур снижает возможность злоупотреблений и повышает уровень защищенности прав и свобод $[11$, с. 171]. В силу такой специфики информация о деятельности органов власти имеет высокую социальную значимость и востребованность.

Здесь важную роль выполняет интернетсреда, дающая возможность выстраивания отношений правительства и граждан, эффективного администрирования и предоставляющая услуги юридическим и физическим лицам. Граждане могут использовать для получения информации официальные сайты органов власти, порталы ре- гиональных правительств, системы поиска нормативно-правовой информации, получать юридические консультации, обсуждать свои проблемы в виртуальном пространстве, задавать вопросы в общественную интернет-приемную, высказывать свое мнение на порталах различных организаций, их форумах [29, с. 54].

Продолжаются дискуссии по вопросам правового регулирования организации государственного управления в аспекте института предоставления публичных услуг. Началом реализации политического курса на организацию системы предоставления государственных и муниципальных услуг гражданам и организациям России в электронном виде является принятие Федерального закона «Об организации предоставления государственных и муниципальных услуг» [19].

Существует различный подход к определению понятия «информационная услуга», законодательные определения основываются на различных критериях.

С точки зрения информационного законодательства все информационные объекты, информационные ресурсы, результаты интеллектуальной деятельности имеют одну общую составляющую информацию, которая определяется как сведения, сообщения, данные независимо от формы их представления [17]. По информационным процессам в первую очередь выделяются услуги: поиска, передачи, распространения, хранения, использования, защиты информации и т.д. С развитием информационных технологий сфера информационных услуг стала значительно шире [8, с. 34].

Государственные услуги предоставляют государственные или муниципальные органы. Гражданско-правовые услуги могут предоставлять физические и юридические лица, государственные и муниципальные предприятия и учреждения. Понятие «информационная услуга» основывается на понятии «информация» и непосредственно связано с информацией, информационными ресурсами и технологиями, которые могут предоставляться различными субъектами публичных и частных правоотношений. Однако единого устойчивого понятия еще не выработано. Таким образом, особенность информационных отношений определяет необходимость дифференцированного подхода к их правовому регулированию на основе комплексного использования методов регулирования разных отраслей права [8, с. 34].

Среди всех разновидностей информации информационные ресурсы органов власти являются самыми востребованными в обществе. Право на доступ к информации является сравнительно новым для Российской Федерации, а законодательство в этой сфере - самым «молодым». 
В настоящее время нормативное регулирование доступа граждан к информации, размещенной в различных источниках, осуществляется с помощью нормативных правовых актов. Нормы права, регулирующие данную сферу, закреплены в Конституции (ст. ст. 15, 24, 29 и др.) [12], в ряде федеральных законов, законов субъектов России и других нормативных правовых актах. Большое значение в укреплении правового порядка данной сферы имеет федеральный закон № 8-ФЗ «Об обеспечении доступа к информации о деятельности государственных органов и органов местного самоуправления» [18].

Правовое информирование является одним из основных направлений деятельности органов государственной власти и местного самоуправления. Проблемы же здесь в основном касаются не столько обеспечения физического доступа к правовой информации, а сколько в ее информационной доступности и полезности $[28$, с. 54]. От их информационной открытости зависит не только их деятельность, но и уровень доверия населения к властям. Помимо этого, согласно «Основам государственной политики в сфере развития правовой грамотности и правосознания граждан», утверждённым 4 мая 2011 г. [24], правовое информирование является мерой государственной политики в области совершенствования законодательства Российской Федерации и правоприменения [28, с. 55].

В данном документе среди мер государства по совершенствованию законодательства и правоприменения можно назвать следующие: 1) создание условий для обеспечения доступности правовой информации; 2) развитие комплекса мер по правовому просвещению граждан; 3) обеспечение функционирования информационно-справочных систем; 4) обеспечение для всех категорий граждан доступности юридических услуг; 5) внедрение практики оказания адвокатами и нотариусами юридических консультаций и содействия гражданам при получении ими государственных услуг, а также их участие в правовом просвещении граждан и развитии правосознания населения [23].
Законом «Об обеспечении доступа к информации о деятельности государственных органов и органов местного самоуправления» закреплен открытый перечень способов доступа к информации о деятельности государственных органов и органов местного самоуправления [18].

Тем не менее меры, указанные в законодательстве, пока недостаточно эффективны для решения имеющихся проблем; существует факторы, мешающие гражданам получать доступную для них правовую информацию посредством сети Интернет. К объективным факторам можно отнести, например, недостаточно качественный уровень публикуемой информации, отсутствие инфраструктуры доступа, к субъективным - невысокий уровень навыков работы с компьютером и интернет-источниками [28, с. 55].

Нормативные акты в процессе правового регулирования предоставления и получения информационных услуг трансформируются и реализуются в комплекс, субъективные права граждан активизируются.

При условии соблюдения необходимого порядка в этой части правореализации - исполнения закона - гражданин переходит из статуса объекта (по концепции организации системы управления) в статус активного субъекта реализации своих прав и обязанностей [2, с. 91].

Таким образом, в условиях перехода к глобальному информационному обществу российская нормативная правовая база в области информационных технологий находится в стадии развития, уточняются правовая терминология, критерии систематизации правового материала.

В нормотворчестве отражается анализ практических подходов к формированию информационной политики государства по взаимодействию с гражданским обществом и решению возникающих проблем, корректируются нормативные правовые акты. В то же время увеличение числа нормативных правовых актов и быстро изменяющаяся ситуация в информационном пространстве порождает проблемы: время подготовки нормативных правовых актов не всегда соответствует изменяющимся условиям, проблематична также интеграция актов по смежным проблемам.

\section{Библиография:}

1. Андреев А. В. Глобализация, информационные технологии и формирование «глобального сетевого общества» // Вестник Кемеровского государственного университета. 2012. № 1 (49). С. 57-61.

2. Бачило И. Л. Государство и право XXI в.: реальное и виртуальное. М.: Юркомпани, 2013. 280 с.

3. Бачило И. Л. О неизбежном продолжении разговора о публичных услугах и более общих проблемах организации государственного управления (по поводу статьи И. Н. Барцица) // Государство и право. 2014. № C. 53-57.

4. Бачило И. Л. Правовая платформа построения электронного государства // Информационное право. - 2008. № 4. С. 3-8.

5. Вершинская О. Н. Информационно-коммуникационные технологии и общество. М.: Наука, 2007. 203 с.

6. Гуменский А. Управление международной информацией // Международные процессы. 2010. Т. 8, № 1. С. 31 -43.

7. Доктрина информационной безопасности Российской Федерации от 9 сентября 2000 г. № ПP-1895. URL: http:// www.scrf.gov.ru/documents/6/5.html (дата обращения 13.10.2015). 


\section{Административное и муниципальное право 1 (97) 2016}

8. Жарова А. К. О подходе к классификации информационно-технологических услуг // Государство и право. 2014. № 3. С. 32-38.

9. Забара И. Н. Деятельность ООН в развитии международно-правового регулирования информационных отношений // Вестник Российского университета дружбы народов. Сер.: юридические науки. 2013. № 1. С. 136-143.

10. Забузов О. Н. Политико-правовые проблемы функционирования сети Интернет // Информационное право. 2015. № 1 . С. 22-26.

11. Колин К. К. Философские проблемы информатики. М.: Бином, 2010. С. 28. 270 с.

12. Конституция Российской Федерации (с поправками от 30 декабря 2008 г., 5 февраля 2014 г.). URL: http://www. iprbookshop.ru/18271.html (дата обращения 13.10.2015).

13. Кучерявый М. М. Глобальное информационное общество и проблемы безопасности // Власть. 2013. № 9. С. 89-92.

14. Магдилов М. М., Магдилова Л. В. Правовые аспекты развития элементов электронного государства в регионе // Вестник Дагестанского государственного университета. 2015. № 2. С. 110-117.

15. Мигбалеев А. В. Отзыв на диссертацию А. И. Химченко на тему «Информационное общество: правовые проблемы в условиях глобализации» // Вестник УРФО. Безопасность в информационной сфере. 2014. № 3 (13). С. 56-60.

16. Новая постиндустриальная волна на западе: антология / под ред. В. Л. Иноземцева. М.: Академия, 1999.640 с.

17. Об информации, информационных технологиях и о защите информации: федеральный закон от 27 июля 2006 г. № 149-Ф3 (ред. от 31.12.2014). URL: http://www.consultant.ru/document/cons_doc_LAW_61798/ (дата обращения 13.10.2015).

18. Об обеспечении доступа к информации о деятельности государственных органов и органов местного самоуправления: федеральный закон от 09 февраля 2009 г. № 8-Ф3 // Собрание законодательства Российской Федерации. 2009. № 7. Ст. 776.

19. Об организации предоставления государственных и муниципальныхуслуг: федеральный закон от 27 июля 2010 г. № 210-Ф3 (ред. от 13.07.2015). URL: http://www.consultant.ru/document/cons_doc_law_103023/ (дата обращения 13.10.2015).

20. Окинавская хартия глобального информационного общества. URL: http://www.unesco.ru/rus/pages/ admin01122004200114.php (дата обращения 13.10.2015).

21. Организация Объединенных Наций в Российской Федерации. URL: http://www.unrussia.ru/ru/agencies/ programma-razvitiya-oon-proon (дата обращения 13.10.2015).

22. Организация Объединенных Наций: офиц. сайт. URL: http://www.un.org/ru/development/ict/res.shtml (дата обращения 13.10.2015).

23. Основы государственной политики Российской Федерации в сфере развития правовой грамотности и правосознания граждан (утв. Президентом РФ 28 апреля 2011 № ПР-1168) http://www.consultant.ru/document/cons_doc_ law_113761/(дата обращения 13.10.2015).

24. Раенко С. И. К вопросу о становлении информационного общества // Наука и современность. 2013. № 20. С. $189-194$.

25. Рейтинг стран мира по уровню развития информационно-коммуникационных технологий 2013: информация об исследовании // Центр гуманитарных технологий. URL: http://gtmarket.ru/ratings/ict-development-index/ictdevelopment-index-info (дата обращения 13.10.2015).

26. Романов А. Н., Жеребин В. М. Развитие информационного общества: Россия в русле глобальной тенденции // Вестник Финансового университета. 2013. № 5 (77). С. 125-135.

27. Сидорина Н. А. Авторское право в России и Германии в условиях информационного общества // Право интеллектуальной собственности. 2010. № 4. С. 15-19.

28. Симагина О., Сергей Ц. Обеспечение доступности государственных услуг // Государственная служба. 2015. № 3 (95). C. 53-59.

29. Стащенко С. П. Компетенция федеральных органов исполнительной власти в сфере предоставления публичных информационных услуг: автореф. дис. ... канд. юрид. наук. М., 2010. 20 с.

30. Стратегия развития информационного общества в Российской Федерации от 7 февраля 2008 г. № ПP-212. URL: http://www.rg.ru/2008/02/16/informacia-strategia-dok.html (дата обращения 13.10.2015).

31. Талимончик В. П. Авторское право в глобальном информационном обществе // Интеллектуальная собственность. авторское право и смежные права. 2011. № 6. С. 67-75.

32. Талимончик В. П. Глобальное информационное общество как комплексный предмет правового регулирования // Закон и право. 2009. № 5. С. 8-11.

33. Талимончик В. П. Роль международной институционной системы в сфере информации в формировании правовой основы глобального информационного общества // Вопросы правоведения. 2009. № 2. С. 90-108.

34. Химченко А. И. Информационное общество в условиях глобализации: правовые аспекты: автореф. дис. ... канд. юрид. наук. М., 2014. 23 с.

35. Шинкарецкая Г. Г. Методы формирования информационного права в глобальном информационном обществе // Вопросы правоведения. 2014. № 4 (26). С. 145-156.

36. Isfandyari-Moghaddam A. Digital solidarities, communication policy and multi-stakeholder global governance: the legacy of the world summit on the information society // European Journal of Communication. 2012. Vol., 27 Iss. 2. P. $197-203$.

37. Janakova M. Challenges of information technologies in the global information society // Proceedings from the 7 th international conference economic policy in the European Union member countries. Trojanovice, 2009. P. 90-100.

38. Li Feng. Global information society: technology, knowledge, and mobility // Economic geography. Vol. 91, iss. 2. P. $229-231$.

39. Mathe V. Reformatting politics information technology and global civil society // Informacios tarsadalom. 2013. Vol. 13, iss. 3-4. P. 100-105. 
40. Measuring the information society report 2014. URL: http://www.itu.int/en/itu-d/statistics/pages/publications/ mis2014.aspx (дата обращения 13.10.2015).

41. Neves B. Information policy, information technology and communication and participation in the information society: focus on digital inclusion from global to local sphere // Transinformacao. 2010. Vol. 22, iss. 1. p. 47-60.

42. В. Н. Шеломенцев Формирование законодательства и эволюциявзглядов российских ученых по проблемамсоотношения государства и гражданскогообщества в первой четверти XX века // Политика и Общество. - 2012. - 3. C. $49-58$.

43. А.С. Емельянов Административно-правовая доктрина, идеилиберализма и развитие государственности в России // Политика и Общество. - 2013. - 2. - C. 220 - 225. DOI: 10.7256/1812-8696.2013.02.13.

44. Липинский Д.A. Social Bases of Positive Responsibility // SENTENTIA. European Journal of Humanities and Social Sciences. - 2015. - 3. - C. 41 - 69. DOI: 10.7256/1339-3057.2015.3.16009. URL: http://www.e-notabene.ru/psen/ article_16009.html

45. Кустова М.В. Правовые проблемы платы за услуги, необходимые и обязательные для предоставления услуг органами публичной власти // Финансовое право и управление. - 2014. - 1. - С. 101 - 109. DOI: 10.7256/23100508.2014.1.9887.

\section{References (transliterated):}

1. Andreev A. V. Globalizatsiya, informatsionnye tekhnologii i formirovanie «global'nogo setevogo obshchestva»// Vestnik Kemerovskogo gosudarstvennogo universiteta. 2012. № 1 (49). S. 57-61.

2. Bachilo I. L. Gosudarstvo i pravo XXI v.: real'noe i virtual'noe. M.: Yurkompani, 2013. $280 \mathrm{~s}$.

3. Bachilo I. L. O neizbezhnom prodolzhenii razgovora o publichnykh uslugakh i bolee obshchikh problemakh organizatsii gosudarstvennogo upravleniya (po povodu stat'i I. N. Bartsitsa) // Gosudarstvo i pravo. 2014. № S. 53-57.

4. Bachilo I. L. Pravovaya platforma postroeniya elektronnogo gosudarstva // Informatsionnoe pravo. - 2008. № 4. C. 3-8.

5. Vershinskaya O. N. Informatsionno-kommunikatsionnye tekhnologii i obshchestvo. M.: Nauka, $2007.203 \mathrm{~s}$.

6. Gumenskii A. Upravlenie mezhdunarodnoi informatsiei // Mezhdunarodnye protsessy. 2010. T. 8, № 1. S. 31-43.

7. Doktrina informatsionnoi bezopasnosti Rossiiskoi Federatsii ot 9 sentyabrya 2000 g. № PR-1895. URL: http://www.scrf. gov.ru/documents/6/5.html (data obrashcheniya 13.10.2015).

8. Zharova A. K. O podkhode k klassifikatsii informatsionno-tekhnologicheskikh uslug // Gosudarstvo i pravo. 2014 . № 3. S. 32-38.

9. Zabara I. N. Deyatel'nost' OON v razvitii mezhdunarodno-pravovogo regulirovaniya informatsionnykh otnoshenii // Vestnik Rossiiskogo universiteta druzhby narodov. Ser.: yuridicheskie nauki. 2013. № 1. S. 136-143.

10. Zabuzov 0. N. Politiko-pravovye problemy funktsionirovaniya seti Internet // Informatsionnoe pravo. 2015. № 1. S. $22-26$.

11. Kolin K. K. Filosofskie problemy informatiki. M.: Binom, 2010. S. 28. 270 s.

12. Konstitutsiya Rossiiskoi Federatsii (s popravkami ot 30 dekabrya 2008 g., 5 fevralya 2014 g.). URL: http://www. iprbookshop.ru/18271.html (data obrashcheniya 13.10.2015).

13. Kucheryavyi M. M. Global'noe informatsionnoe obshchestvo i problemy bezopasnosti // Vlast'. 2013. № 9. S. 89-92.

14. Magdilov M. M., Magdilova L. V. Pravovye aspekty razvitiya elementov elektronnogo gosudarstva v regione // Vestnik Dagestanskogo gosudarstvennogo universiteta. 2015. № 2. S. 110-117.

15. Migbaleev A. V. Otzyv na dissertatsiyu A. I. Khimchenko na temu «Informatsionnoe obshchestvo: pravovye problemy v usloviyakh globalizatsii» // Vestnik URFO. Bezopasnost' v informatsionnoi sfere. 2014. № 3 (13). S. 56-60.

16. Novaya postindustrial'naya volna na zapade: antologiya / pod red. V. L. Inozemtseva. M.: Akademiya, $1999.640 \mathrm{~s}$.

17. Ob informatsii, informatsionnykh tekhnologiyakh i o zashchite informatsii: federal'nyi zakon ot 27 iyulya 2006 g. № 149-FZ (red. ot 31.12.2014). URL: http://www.consultant.ru/document/cons_doc_LAW_61798/ (data obrashcheniya 13.10.2015).

18. Ob obespechenii dostupa k informatsii o deyatel'nosti gosudarstvennykh organov i organov mestnogo samoupravleniya: federal'nyi zakon ot 09 fevralya 2009 g. № 8-FZ // Sobranie zakonodatel'stva Rossiiskoi Federatsii. 2009. № 7. St. 776.

19. Ob organizatsii predostavleniya gosudarstvennykh i munitsipal'nykh uslug: federal'nyi zakon ot 27 iyulya 2010 g. № 210 -FZ (red. ot 13.07.2015). URL: http://www.consultant.ru/document/cons_doc_law_103023/ (data obrashcheniya 13.10.2015).

20. Okinavskaya khartiya global'nogo informatsionnogo obshchestva. URL: http://www.unesco.ru/rus/pages/ admin 01122004200114.php (data obrashcheniya 13.10.2015).

21. Organizatsiya Ob"edinennykh Natsii v Rossiiskoi Federatsii. URL: http://www.unrussia.ru/ru/agencies/programmarazvitiya-oon-proon (data obrashcheniya 13.10.2015).

22. Organizatsiya Ob"edinennykh Natsii: ofits. sait. URL: http://www.un.org/ru/development/ict/res.shtml (data obrashcheniya 13.10.2015).

23. Osnovy gosudarstvennoi politiki Rossiiskoi Federatsii v sfere razvitiya pravovoi gramotnosti i pravosoznaniya grazhdan (utv. Prezidentom RF 28 aprelya 2011 № PR-1168) http://www.consultant.ru/document/cons_doc_law_113761/(data obrashcheniya 13.10.2015).

24. Raenko S. I. K voprosu o stanovlenii informatsionnogo obshchestva // Nauka i sovremennost'. 2013. № 20. S. 189-194.

25. Reiting stran mira po urovnyu razvitiya informatsionno-kommunikatsionnykh tekhnologii 2013: informatsiya ob issledovanii // Tsentr gumanitarnykh tekhnologii. URL: http://gtmarket.ru/ratings/ict-development-index/ictdevelopment-index-info (data obrashcheniya 13.10.2015).

26. Romanov A. N., Zherebin V. M. Razvitie informatsionnogo obshchestva: Rossiya v rusle global'noi tendentsii // Vestnik Finansovogo universiteta. 2013. № 5 (77). S. 125-135. 


\section{Административное и муниципальное право 1 (97) • 2016}

27. Sidorina N. A. Avtorskoe pravo v Rossii i Germanii v usloviyakh informatsionnogo obshchestva // Pravo intellektual'noi sobstvennosti. 2010. № 4. S. 15-19.

28. Simagina O., Sergei Ts. Obespechenie dostupnosti gosudarstvennykh uslug // Gosudarstvennaya sluzhba. 2015. № 3 (95). S. 53-59.

29. Stashchenko S. P. Kompetentsiya federal'nykh organov ispolnitel'noi vlasti $\mathrm{v}$ sfere predostavleniya publichnykh informatsionnykh uslug: avtoref. dis. ... kand. yurid. nauk. M., 2010. 20 s.

30. Ctrategiya razvitiya informatsionnogo obshchestva v Rossiiskoi Federatsii ot 7 fevralya 2008 g. № PR-212. URL: http:// www.rg.ru/2008/02/16/informacia-strategia-dok.html (data obrashcheniya 13.10.2015).

31. Talimonchik V. P. Avtorskoe pravo v global'nom informatsionnom obshchestve // Intellektual'naya sobstvennost'. avtorskoe pravo i smezhnye prava. 2011. № 6. S. 67-75.

32. Talimonchik V. P. Global'noe informatsionnoe obshchestvo kak kompleksnyi predmet pravovogo regulirovaniya // Zakon i pravo. 2009. № 5. S. 8-11.

33. Talimonchik V. P. Rol' mezhdunarodnoi institutsionnoi sistemy v sfere informatsii $\mathrm{v}$ formirovanii pravovoi osnovy global'nogo informatsionnogo obshchestva // Voprosy pravovedeniya. 2009. № 2. S. 90-108.

34. Khimchenko A. I. Informatsionnoe obshchestvo v usloviyakh globalizatsii: pravovye aspekty: avtoref. dis. ... kand. yurid. nauk. M., 2014. $23 \mathrm{~s}$.

35. Shinkaretskaya G. G. Metody formirovaniya informatsionnogo prava v global'nom informatsionnom obshchestve // Voprosy pravovedeniya. 2014. № 4 (26). S. 145-156.

36. Isfandyari-Moghaddam A. Digital solidarities, communication policy and multi-stakeholder global governance: the legacy of the world summit on the information society // European Journal of Communication. 2012. Vol., 27 Iss. 2. P. 197-203.

37. Janakova M. Shallenges of information technologies in the global information society // Proceedings from the 7th international conference economic policy in the European Union member countries. Trojanovice, 2009. P. 90-100.

38. Li Feng. Global information society: technology, knowledge, and mobility // Economic geography. Vol. 91, iss. 2. P. 229231.

39. Mathe V. Reformatting politics information technology and global civil society // Informacios tarsadalom. 2013. Vol. 13, iss. 3-4. P. 100-105.

40. Measuring the information society report 2014. URL: http://www.itu.int/en/itu-d/statistics/pages/publications/ mis2014.aspx (data obrashcheniya 13.10.2015).

41. Neves B. Information policy, information technology and communication and participation in the information society: focus on digital inclusion from global to local sphere // Transinformacao. 2010. Vol. 22, iss. 1. r. 47-60.

42. V.N.ShelomentsevFormirovaniezakonodatel'stvaievolyutsiyavzglyadovrossiiskikhuchenykh poproblemamsootnosheniya gosudarstva i grazhdanskogoobshchestva v pervoi chetverti XX veka // Politika i Obshchestvo. - 2012. - 3. - C. 49 - 58.

43. A.S. Emel'yanov Administrativno-pravovaya doktrina, ideiliberalizma i razvitie gosudarstvennosti v Rossii // Politika i Obshchestvo. - 2013. - 2. - C. 220 - 225. DOI: 10.7256/1812-8696.2013.02.13.

44. Lipinskii D.A. Social Bases of Positive Responsibility // SENTENTIA. European Journal of Humanities and Social Sciences. - 2015. - 3. - C. 41 - 69. DOI: 10.7256/1339-3057.2015.3.16009. URL: http://www.e-notabene.ru/psen/article_16009. html

45. Kustova M.V. Pravovye problemy platy za uslugi, neobkhodimye i obyazatel'nye dlya predostavleniya uslug organami publichnoi vlasti // Finansovoe pravo i upravlenie. - 2014. - 1. - C. 101 - 109. DOI: 10.7256/2310-0508.2014.1.9887. 